\title{
Biomechanical evaluation of lumbar pedicle screws in spondylolytic vertebrae: comparison of fixation strength between the traditional trajectory and a cortical bone trajectory
}

\author{
Keitaro Matsukawa, MD, PhD, ${ }^{1}$ Yoshiyuki Yato, MD, PhD, ${ }^{2}$ Hideaki Imabayashi, MD, PhD, ${ }^{1}$ \\ Naobumi Hosogane, MD, PhD, ${ }^{1}$ Takashi Asazuma, MD, PhD, ${ }^{2}$ and Kazuhiro Chiba, MD, PhD ${ }^{1}$ \\ 1Department of Orthopaedic Surgery, National Defense Medical College, Tokorozawa, Saitama; and 'Department of Orthopaedic \\ Surgery, National Hospital Organization, Murayama Medical Center, Musashimurayama, Tokyo, Japan
}

\begin{abstract}
OBJECTIVE In the management of isthmic spondylolisthesis, the pedicle screw system is widely accepted surgical strategy; however, there are few reports on the biomechanical behavior of pedicle screws in spondylolytic vertebrae. The purpose of the present study was to compare fixation strength between pedicle screws inserted through the traditional trajectory (TT) and those inserted through a cortical bone trajectory (CBT) in spondylolytic vertebrae by computational simulation.

METHODS Finite element models of spondylolytic and normal vertebrae were created from CT scans of 17 patients with adult isthmic spondylolisthesis (mean age 54.6 years, 10 men and 7 women). Each vertebral model was implanted with pedicle screws using TT and CBT techniques and compared between two groups. First, fixation strength of a single screw was evaluated by measuring axial pullout strength. Next, vertebral fixation strength of a paired-screw construct was examined by applying forces simulating flexion, extension, lateral bending, and axial rotation to vertebrae.
\end{abstract}

RESULTS Fixation strengths of TT screws showed a nonsignificant difference between the spondylolytic and the normal vertebrae $(p=0.31-0.81)$. Fixation strength of CBT screws in the spondylolytic vertebrae demonstrated a statistically significant decrease in pullout strength $(21.4 \%, p<0.01)$, flexion $(44.1 \%, p<0.01)$, extension $(40.9 \%, p<0.01)$, lateral bending $(38.3 \%, p<0.01)$, and axial rotation $(28.1 \%, p<0.05)$ compared with those in the normal vertebrae. In the spondylolytic vertebrae, no statistically significant difference was observed for pullout strength between TT and CBT $(p=0.90)$; however, the CBT construct showed lower vertebral fixation strength in flexion $(39.0 \%, p<0.01)$, extension $(35.6 \%, p<0.01)$, lateral bending $(50.7 \%, p<0.01)$, and axial rotation $(59.3 \%, p<0.01)$ compared with the TT construct. CONCLUSIONS CBT screws are less optimal for stabilizing the spondylolytic vertebra due to their lower fixation strength compared with TT screws.

http://thejns.org/doi/abs/10.3171/2015.11.SPINE15926

KEY WORDS spondylolysis; isthmic spondylolisthesis; cortical bone trajectory; lumbar pedicle screw; fixation strength; finite element analysis; degenerative

$\mathrm{S}$ PONDYLOLYSIS, which is defined as an anatomical defect in the pars interarticularis of a vertebra, is not a rare condition in the general adult population.., 20 This defect allows separation of the vertebral body from the lamina and inferior facet joint and decreases the stabilizing ability of the posterior element, thus leading to anterior translation of the affected vertebra. Although the intervertebral disc is the main structure opposing the anteriorly directed shear force, ${ }^{5}$ progression of spondylolis- thesis causes lower back pain, and in some patients, severe leg pain due to foraminal stenosis. Operative treatments are often necessary in patients whose neurological symptoms are unresponsive to conservative treatments. The basic principle of surgery is neurological decompression and spinal reconstruction. Pedicle screw systems have been widely used due to their rigid fixation property, which provides correct spinal alignment and maintains stability until bone arthrodesis is obtained. Over the past few de- 
cades, a considerable number of reports on surgical treatment of isthmic spondylolisthesis have shown favorable clinical outcomes; ${ }^{4,10,12}$ however, to the best of our knowledge, there are few reports describing the biomechanical behavior of pedicle screws in spondylolytic vertebrae. The anterior anchoring capacity of pedicle screws is critical because the posterior vertebral element is disrupted and fails to effectively distribute the load applied to the vertebra.

The aims of the present study were to compare the fixation strength between pedicle screws placed in normal and spondylolytic vertebrae, and to compare the fixation strength between pedicle screws inserted using cortical bone trajectory (CBT), which was proposed by Santoni et al., ${ }^{22}$ and those inserted using a traditional trajectory (TT). While CBT takes advantage of maximizing the engagement with cortical bone and provides enhanced screw purchase, ${ }^{1,15,16,22}$ there is little consensus on the indication of CBT for patients with spondylolysis.

\section{Methods \\ Finite Element Models}

The CT scans of 17 patients who underwent surgery for adult isthmic spondylolisthesis (mean amount of slippage $19.6 \% \pm 4.2 \%$ ) were used. There were 10 men and 7 women, with a mean age of $54.6 \pm 12.9$ years (range 35-82 years). The levels of spondylolisthesis were L-4 in 3 patients and L-5 in 14 patients. The 3D finite element (FE) models of the spondylolytic vertebra were created from the CT data, with a slice thickness of $1 \mathrm{~mm}$ using Mechanical Finder software (version 6.2, extended edition; Research Center of Computational Mechanics). Normal vertebral models were also created using the data of the vertebra 1 level cranial to the affected segment of the same individuals, and served as controls. The details of the FE model construction were described previously. ${ }^{14,15}$ FE models of pedicle screws (SOLERA Spinal System, Medtronic) were developed separately from high-resolution micro-CT data and were assigned the material properties of cobalt chromium alloy for the screw heads and titanium alloy for the screw shafts. Each bone model was implanted with pedicle screws using the TT and CBT techniques (Fig. 1). TT screws were inserted into the vertebral body along the anatomical axis of the pedicle and parallel to the vertebral endplate using Weinstein's technique. ${ }^{25}$ Based on our previous morphometric study, ${ }^{17} \mathrm{CBT}$ screws were inserted $10^{\circ}$ laterally in the axial plane and $25^{\circ}$ cranially in the sagittal plane through the midpoint of the pedicle. To simulate the actual clinical situation, we used TT screws of $6.5 \mathrm{~mm}$ in diameter and $40 \mathrm{~mm}$ in length, and CBT screws of 5.5 $\mathrm{mm}$ in diameter and $35 \mathrm{~mm}$ in length. All screws were carefully placed in an appropriate position without any cortical breaching or penetration into the anterior vertebral cortex that might influence screw fixation strength. These FE models were divided into 0.5-1-mm tetrahedral solid elements to reflect the smooth surface using the automatic mesh function of the software. The bone-screw interface characteristics were set to contact conditions and the friction coefficient was determined to be zero, based on previous studies. ${ }^{7,14,15}$
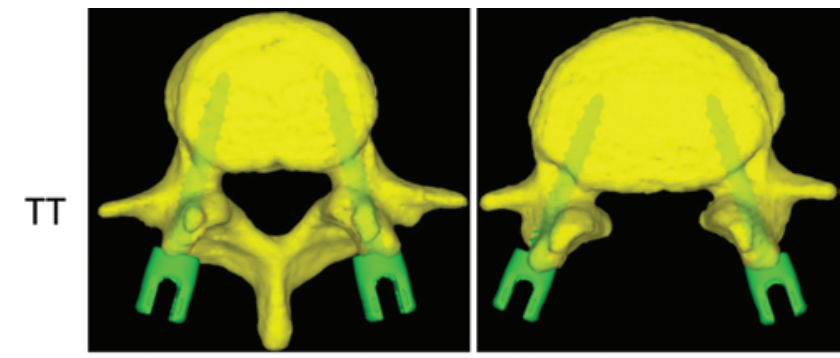

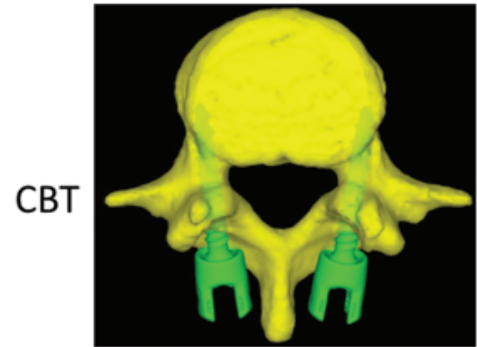

Normal Vertebra

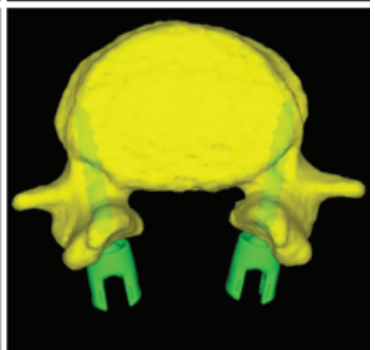

Spondylolytic Vertebra
FIG. 1. FE models. Upper: Normal vertebra (left) and spondylolytic vertebra (right) with pedicle screws inserted via the TT. Lower: Normal vertebra (left) and spondylolytic vertebra (right) with pedicle screws inserted via the CBT. Figure is available in color online only.

\section{Loading and Boundary Conditions}

In each model, nonlinear FE analysis was performed. First, pullout force was applied to the screw head along the longitudinal axis of the screw with an incremental loading rate of $20 \mathrm{~N}$, and the vertebral body was completely fixed in all directions at the superior and inferior surfaces of the vertebral endplates. ${ }^{14,15}$ The displacement was measured at the screw head, and the pullout strength was defined as the load at the point where the load-displacement curve increased abruptly.

Next, to evaluate the vertebral fixation strength, each vertebra was implanted with bilateral pedicle screws. Both screw heads were rigidly fixed in the conditions reported by Chen et al. ${ }^{3}$ An incremental loading rate of $20 \mathrm{~N}$ was gradually applied to the surfaces of the vertebral body to simulate flexion, extension, lateral bending, and axial rotation loads according to prior testing protocols (Fig. 2). ${ }^{15}$

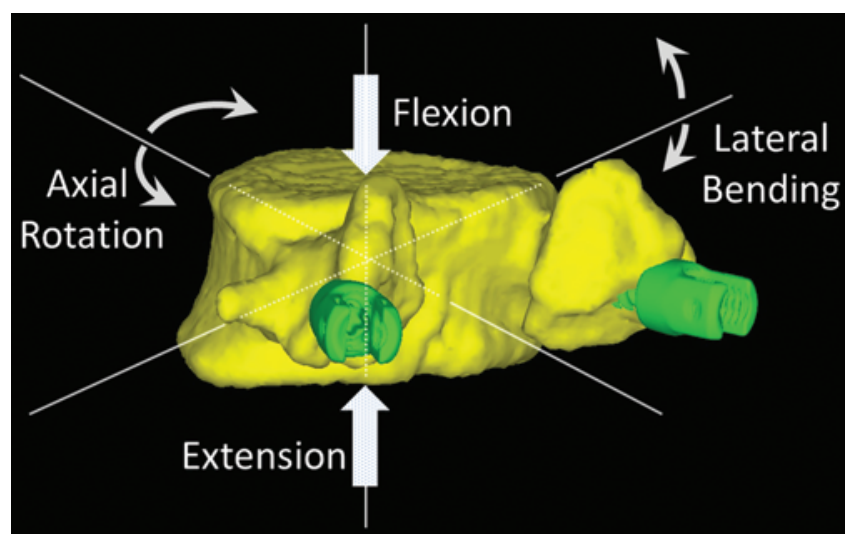

FIG. 2. Illustration of loading conditions for flexion, extension, lateral bending, and axial rotation. Figure is available in color online only. 
Under destructive loading, the displacement was obtained from the average movement of the whole vertebra, and the ultimate failure loads were defined as the load at the inflection point of the load-displacement curve. Vertebral fixation strength $(\mathrm{N} / \mathrm{mm})$ was defined as the slope of the line fitting the load-displacement curve until the ultimate failure load. The computer solution time per analysis ranged from 12 to 36 hours, and a total of 340 biomechanical analyses were performed on models simulating the 17 individuals.

\section{Statistical Analyses}

All results are shown as means \pm standard deviations. The data were compared using the paired t-test and Student t-test. JMP software (version 10, SAS) was used for all analyses and significance was defined as $\mathrm{p}<0.05$.

\section{Results}

\section{Normal Compared With Spondylolytic Vertebrae}

The mean pullout strength of TT screws was $1125 \pm$ $286 \mathrm{~N}$ for the normal vertebrae and $1094 \pm 276 \mathrm{~N}$ for the spondylolytic vertebrae; this difference was not significant $(\mathrm{p}=0.81)$. The mean pullout strength of CBT screws was $1380 \pm 334 \mathrm{~N}$ for the normal vertebrae and $1085 \pm 302$ $\mathrm{N}$ for the spondylolytic vertebrae. The spondylolytic vertebrae demonstrated a $21.4 \%$ lower pullout strength than the normal vertebrae, and this difference was statistically significant $(\mathrm{p}<0.01$; Fig. 3$)$. In terms of vertebral fixation strength, the TT construct showed no significant difference between the spondylolytic and the normal vertebrae in all directions of motion ( $p=0.31-0.81$; Fig. 4). As for the CBT construct, the spondylolytic vertebrae showed significantly lower fixation strength in flexion $(44.1 \%, \mathrm{p}<$ $0.01)$, extension $(40.9 \%, \mathrm{p}<0.01)$, lateral bending $(38.3 \%$, $\mathrm{p}<0.01)$, and axial rotation $(28.1 \%, \mathrm{p}<0.05)$ than the normal vertebrae (Fig. 5).

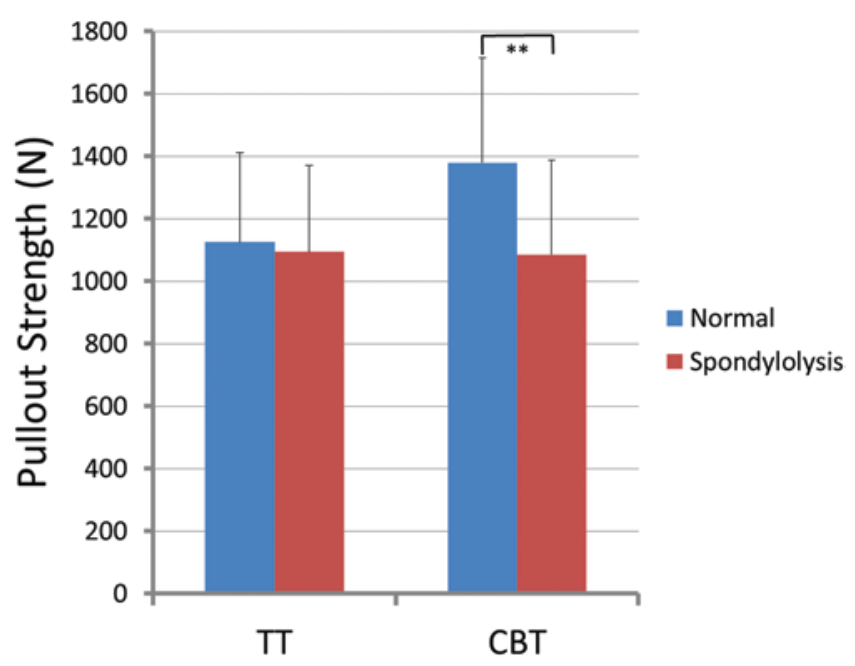

FIG. 3. Graph comparing mean pullout strength. The pullout strength of CBT screws in the spondylolytic vertebrae was significantly lower than that in the normal vertebrae. ${ }^{* *} p<0.01$. Figure is available in color online only.

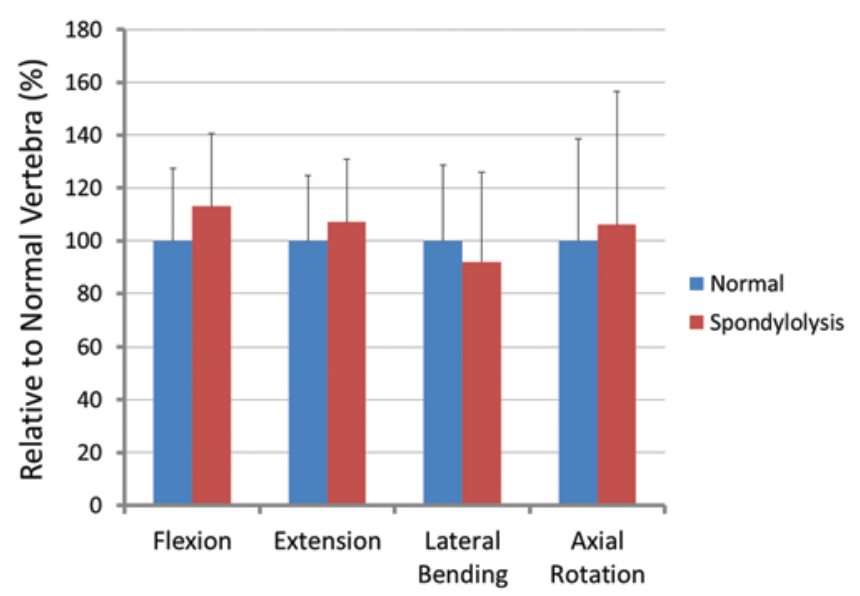

FIG. 4. Graph comparing the vertebral fixation strength of screws inserted using a TT between normal and spondylolytic vertebrae. The fixation strength of the normal vertebrae was set to $100 \%$. No statistically significant differences were observed. Figure is available in color online only.

\section{Traditional Compared With Cortical Bone Trajectory}

In the normal vertebrae, CBT screws demonstrated higher pullout strength $(23.4 \%, \mathrm{p}<0.05)$, higher vertebral fixation strength in flexion $(36.4 \%, \mathrm{p}<0.01)$ and extension $(23.8 \%, \mathrm{p}<0.05)$, and lower strength in lateral bending $(17.4 \%, \mathrm{p}=0.26)$ and axial rotation $(36.3 \%, \mathrm{p}<0.01)$ than TT screws (Fig. 6). In the spondylolytic vertebrae, no statistically significant difference was observed in the pullout strength between TT and CBT $(\mathrm{p}=0.90)$; however, the CBT construct showed lower vertebral fixation strength in flexion $(39.0 \%, \mathrm{p}<0.01)$, extension $(35.6 \%, \mathrm{p}<0.01)$, lateral bending $(50.7 \%, \mathrm{p}<0.01)$, and axial rotation $(59.3 \%, \mathrm{p}$ $<0.01$ ) compared with the TT construct (Fig. 7).

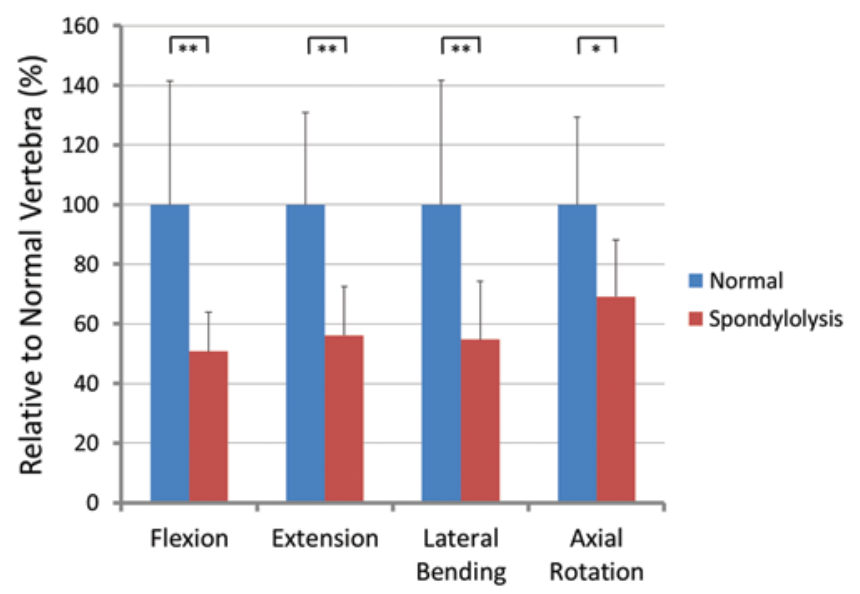

FIG. 5. Graph comparing the vertebral fixation strength of screws inserted using CBT between normal and spondylolytic vertebrae. The fixation strength of the normal vertebrae was set to $100 \%$. The spondylolytic vertebrae demonstrated significantly lower fixation strength in each plane of motion. ${ }^{*} p<0.05,{ }^{*} p<0.01$. Figure is available in color online only. 


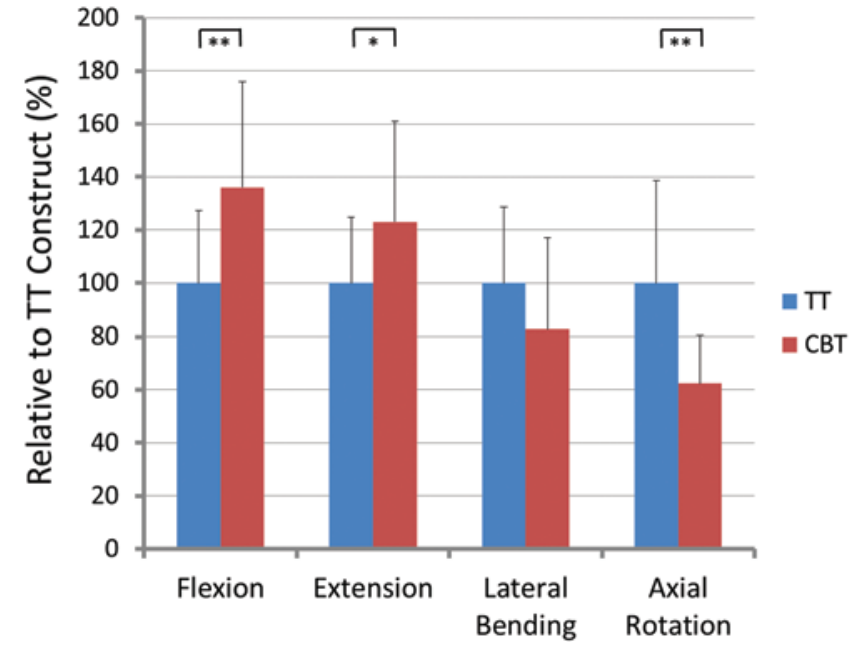

FIG. 6. Graph comparing vertebral fixation strength between the TT and CBT in normal vertebrae. The fixation strength of the TT construct was set to $100 \%$. The CBT construct showed greater strength in flexion and extension and lower strength in lateral bending and axial rotation. ${ }^{*} p<$ $0.05,{ }^{* *} p<0.01$. Figure is available in color online only.

\section{Discussion}

The pars interarticularis is a key component in segmental stability. Mihara et al. conducted a biomechanical study using the calf lumbar spine and showed that bilateral pars interarticularis defects increased intervertebral mobility ${ }^{18}$ Previous studies using flexion-extension radiographs on the kinematics of the vertebrae in patients with spondylolysis also revealed abnormal movements in the affected segment compared with the normal segment. ${ }^{21,23}$ These alterations in motion potentially lead to progressive disc degeneration and anterior vertebral subluxation. Pedicle screw systems have typically been used to reconstruct the vertebral column against such anterior slipping. The present study is the first to evaluate the fixation strength of pedicle screws inserted through different trajectories into the spondylolytic vertebra. Cadaveric spines are useful for evaluating the biomechanical behavior of pedicle screws, but there are some difficulties that may cause biased study results, including insufficient sample size, wide individual variations of bone quality and age, and validity of morphological conditions of spondylolysis. FE analysis, which has been increasingly used in experiments related to the spine, ${ }^{2,3,7,14,15}$ allows a fair comparison by flexibly changing the parameters of interest under the same environmental conditions. Therefore, we considered FE analysis to be suitable to investigate the underlying biomechanical mechanism and used models of a single vertebral segment to prove the fixation strength of the inserted screws.

A comparison between the normal and spondylolytic vertebrae revealed that both pullout strength and vertebral fixation strength of TT screws were equivalent. One explanation for this result is that the fixation strength of TT screws relies mainly on the engagement of trabecular bone within the pedicle, which is preserved even in the spondylolytic vertebra. A sufficient number of biomechanical stud-

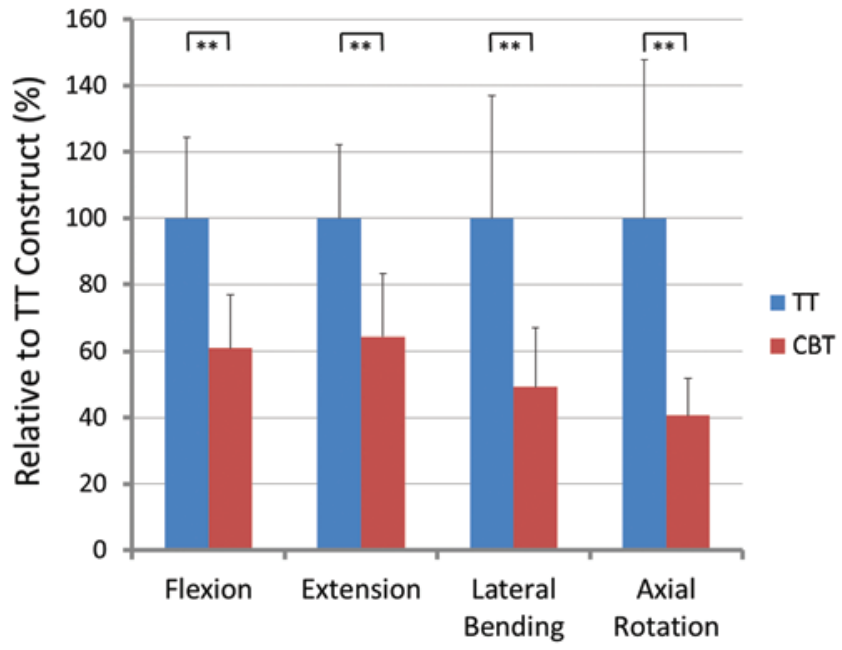

FIG. 7. Comparison of vertebral fixation strength between the TT and $\mathrm{CBT}$ in the spondylolytic vertebrae. The fixation strength of the TT construct was set to $100 \%$. The CBT construct showed significantly lower fixation strength in each plane of motion. ${ }^{* *} p<0.01$. Figure is available in color online only.

ies have been performed to confirm the importance of the pedicle in the fixation ability of pedicle screws. Hirano et al. reported that $60 \%-80 \%$ of the fixation strength of pedicle screws depended on the pedicle along its screw path. ${ }^{6}$ Another report by Myers et al. showed that regional bone mineral density of the pedicle was the most useful predictor of screw fixation strength compared with regional bone mineral density of the vertebral body. ${ }^{19}$ In contrast, the fixation strength of CBT screws in the spondylolytic vertebrae decreased approximately $20 \%$ in pullout strength, $40 \%$ in vertebral flexion/extension/lateral bending loading, and $30 \%$ in axial rotation compared with those in the normal vertebrae. We had initially assumed that CBT screws would demonstrate favorable fixation strength by penetrating the sclerotic surface at the pars defect, but the results were opposite to this assumption. This may be due to the absence of solid purchase of the cortical bone of the lamina. From an anatomical point of view, cortical bone is most concentrated between the pars interarticularis region and the inferior part of the pedicle. ${ }^{8,14,24}$ Our previous study on the fixation strength of CBT has revealed that obtaining maximum contact with the lamina was a crucial factor in gaining optimal fixation strength. ${ }^{13}$ The spondylolytic vertebra lacks the pars and adjacent lamina on which CBT screws rely for most of their stability.

CBT was developed as a less invasive alternative to TT for lumbar fusion; therefore, we compared the fixation strength of CBT screws with that of TT screws. CBT screws demonstrated higher pullout strength, and the CBT construct had superior resistance to flexion/extension loads and inferior resistance to lateral bending and axial rotation loads in the normal vertebrae, which are consistent with our previous biomechanical study. ${ }^{15}$ However, in the spondylolytic vertebrae, CBT screws provided similar pullout strength to TT screws, but the CBT construct showed significantly lower vertebral fixation strength than 
the TT construct in all planes of motion. The lack of cortical purchase in the posterior lamina and the divergent and short lever arm of CBT screws appeared to be the cause of this drawback. To achieve better bone fixation, surgeons need to recognize the fixation strength of the paired-screw construct rather than that of a single screw. From these biomechanical points of view, we recommend TT for spondylolytic vertebrae over CBT, even though the latter can reduce muscle dissection and is less invasive.

There are some limitations to this study that should be mentioned. First, we used CT scans of only 17 patients, a relatively small number of subjects. However, the effect sizes given by Cohen's d statistic (CBT construct of the normal vertebrae vs CBT construct of the spondylolytic vertebrae, TT construct of the spondylolytic vertebrae vs CBT construct of the spondylolytic vertebrae) were very large $(\mathrm{d}=1.24-1.89)$ and power analyses revealed that this sample size was large enough to detect a statistical difference between the two groups $(1-\beta>0.9)$. Next, we used vertebrae 1 level cranial to the affected segment within the same individuals as controls to minimize the effect of age and bone quality. However, the morphology of the vertebra, such as shape, size, and convergence of the pedicle, differs among different lumbar levels, so additional investigation comparing the same lumbar level may be necessary. Lastly, the loading conditions of the present study do not perfectly replicate the actual loads acting on the construct in vivo. Law et al. reported the importance of caudocephalad cyclic loading as a mechanism of pedicle screw loosening ${ }^{11}$ however, the FE models have difficulty in testing the effects of cyclic loading. Moreover, we analyzed the FE models of the single vertebral segment. Although a multiple-segment and screw-rod construct model provides a better representation of the actual clinical situation, the inclusion of a motion segment requires more complex information on material properties and geometry of the intervertebral elements and facet joints, leading to more complicated results. We believe that the models in the present study are useful to evaluate the straightforward holding power of inserted screws. It is unclear what level of stiffness is ideal for spinal fixation; therefore, further investigations with clinical and radiographic results and cadaveric study using spondylolytic vertebrae are necessary.

\section{Conclusions}

The biomechanical behavior of pedicle screws inserted into spondylolytic vertebrae has been demonstrated in this study. CBT screws are less optimal for stabilizing the spondylolytic vertebra due to its lower fixation strength compared with TT screws.

\section{References}

1. Baluch DA, Patel AA, Lullo B, Havey RM, Voronov LI, Nguyen NL, et al: Effect of physiological loads on cortical and traditional pedicle screw fixation. Spine (Phila Pa 1976) 39:E1297-E1302, 2014

2. Bianco RJ, Arnoux PJ, Wagnac E, Mac-Thiong JM, Aubin $\mathrm{CE}$ : Minimizing pedicle screw pullout risks: a detailed biomechanical analysis of screw design and placement. J Spinal Disord Tech [epub ahead of print], 2014
3. Chen SI, Lin RM, Chang CH: Biomechanical investigation of pedicle screw-vertebrae complex: a finite element approach using bonded and contact interface conditions. Med Eng Phys 25:275-282, 2003

4. Cunningham JE, Elling EM, Milton AH, Robertson PA: What is the optimum fusion technique for adult isthmic spondylolisthesis-PLIF or PLF? A long-term prospective cohort comparison study. J Spinal Disord Tech 26:260-267, 2013

5. Floman Y: Progression of lumbosacral isthmic spondylolisthesis in adults. Spine (Phila Pa 1976) 25:342347,2000

6. Hirano T, Hasegawa K, Takahashi HE, Uchiyama S, Hara T, Washio T, et al: Structural characteristics of the pedicle and its role in screw stability. Spine (Phila Pa 1976) 22:25042510,1997

7. Hsu CC, Chao CK, Wang JL, Hou SM, Tsai YT, Lin J: Increase of pullout strength of spinal pedicle screws with conical core: biomechanical tests and finite element analyses. J Orthop Res 23:788-794, 2005

8. Ivanov AA, Faizan A, Ebraheim NA, Yeasting R, Goel VK: The effect of removing the lateral part of the pars interarticularis on stress distribution at the neural arch in lumbar foraminal microdecompression at L3-L4 and L4L5: anatomic and finite element investigations. Spine (Phila Pa 1976) 32:2462-2466, 2007

9. Kalichman L, Kim DH, Li L, Guermazi A, Berkin V, Hunter DJ: Spondylolysis and spondylolisthesis: prevalence and association with low back pain in the adult community-based population. Spine (Phila Pa 1976) 34:199-205, 2009

10. La Rosa G, Conti A, Cacciola F, Cardali S, La Torre D, Gambadauro NM, et al: Pedicle screw fixation for isthmic spondylolisthesis: does posterior lumbar interbody fusion improve outcome over posterolateral fusion? J Neurosurg 99 (2 Suppl):143-150, 2003

11. Law M, Tencer AF, Anderson PA: Caudo-cephalad loading of pedicle screws: mechanisms of loosening and methods of augmentation. Spine (Phila Pa 1976) 18:2438-2443, 1993

12. Lian XF, Hou TS, Xu JG, Zeng BF, Zhao J, Liu XK, et al: Single segment of posterior lumbar interbody fusion for adult isthmic spondylolisthesis: reduction or fusion in situ. Eur Spine J 23:172-179, 2014

13. Matsukawa K, Taguchi E, Yato Y, Imabayashi H, Hosogane $\mathrm{N}$, Asazuma T, et al: Evaluation of the fixation strength of pedicle screws using cortical bone trajectory: what is the ideal trajectory for optimal fixation? Spine (Phila Pa 1976) 40:E873-E878, 2015

14. Matsukawa K, Yato Y, Hynes RA, Imabayashi H, Hosogane $\mathrm{N}$, Yoshihara Y, et al: Comparison of pedicle screw fixation strength among different transpedicular trajectories: a finite element study. J Spinal Disord Tech [epub ahead of print], 2015

15. Matsukawa K, Yato Y, Imabayashi H, Hosogane N, Asazuma T, Nemoto K: Biomechanical evaluation of the fixation strength of lumbar pedicle screws using cortical bone trajectory: a finite element study. J Neurosurg Spine 23:471-478, 2015

16. Matsukawa K, Yato Y, Kato T, Imabayashi H, Asazuma T, Nemoto K: In vivo analysis of insertional torque during pedicle screwing using cortical bone trajectory technique. Spine (Phila Pa 1976) 39:E240-E245, 2014

17. Matsukawa K, Yato Y, Nemoto O, Imabayashi H, Asazuma T, Nemoto K: Morphometric measurement of cortical bone trajectory for lumbar pedicle screw insertion using computed tomography. J Spinal Disord Tech 26:E248E253, 2013

18. Mihara H, Onari K, Cheng BC, David SM, Zdeblick TA: The biomechanical effects of spondylolysis and its treatment. Spine (Phila Pa 1976) 28:235-238, 2003 
19. Myers BS, Belmont PJ Jr, Richardson WJ, Yu JR, Harper $\mathrm{KD}$, Nightingale RW: The role of imaging and in situ biomechanical testing in assessing pedicle screw pull-out strength. Spine (Phila Pa 1976) 21:1962-1968, 1996

20. Sakai T, Sairyo K, Takao S, Nishitani H, Yasui N: Incidence of lumbar spondylolysis in the general population in Japan based on multidetector computed tomography scans from two thousand subjects. Spine (Phila Pa 1976) 34:2346-2350, 2009

21. Sakamaki T, Katoh S, Sairyo K: Normal and spondylolytic pediatric spine movements with reference to instantaneous axis of rotation. Spine (Phila Pa 1976) 27:141-145, 2002

22. Santoni BG, Hynes RA, McGilvray KC, Rodriguez-Canessa G, Lyons AS, Henson MAW, et al: Cortical bone trajectory for lumbar pedicle screws. Spine J 9:366-373, 2009

23. Schneider G, Pearcy MJ, Bogduk N: Abnormal motion in spondylolytic spondylolisthesis. Spine (Phila Pa 1976) 30:1159-1164, 2005

24. Weiner BK, Walker M, Wiley W, McCulloch JA: The lateral buttress: an anatomic feature of the lumbar pars interarticularis. Spine (Phila Pa 1976) 27:E385-E387, 2002

25. Weinstein JN, Spratt KF, Spengler D, Brick C, Reid S: Spinal pedicle fixation: reliability and validity of roentgenogram-based assessment and surgical factors on successful screw placement. Spine (Phila Pa 1976) 13:1012-1018, 1988

\section{Disclosures}

The authors report no conflict of interest concerning the materials or methods used in this study or the findings specified in this paper.

\section{Author Contributions}

Conception and design: Matsukawa. Acquisition of data: Matsukawa, Yato, Hosogane. Analysis and interpretation of data: Matsukawa. Drafting the article: Matsukawa. Critically revising the article: Yato, Asazuma, Chiba. Reviewed submitted version of manuscript: Matsukawa, Hosogane. Approved the final version of the manuscript on behalf of all authors: Matsukawa. Statistical analysis: Matsukawa, Imabayashi. Administrative/technical/material support: Matsukawa, Yato, Imabayashi. Study supervision: Yato, Chiba.

\section{Correspondence}

Keitaro Matsukawa, Department of Orthopaedic Surgery, National Defense Medical College, 3-2 Namiki, Tokorozawa, Saitama 359-8513, Japan. email: keitaro197897@ hotmail.com. 